\title{
C\&RL News guidelines for submission of articles or columns
}

\section{A statement of purpose and content for College \& Research Libraries News.}

\section{$\mathbf{P}$}

urpose of C\&RL News

College \& Research Libraries News is the official news magazine of the Association of College \& Research Libraries, a division of the American Library Association. Its purpose is to record significant activities of ACRL and to report news about academic and research libraries. As the official ACRL news magazine, C\&RL News maintains a record of selected actions and policy statements of the Association and publishes timely reports on the activities of ACRL and its sections, committees, discussion groups, councils, task forces, and chapters.

As a vehicle for communication among college and research libraries, C\&RL News reports news items pertinent to academic and research librarianship, including information on bibliographic instruction, continuing education, appointments, acquisition of special collections, grants to libraries, new technology, and publications (brief notices).

The editor bears responsibility for the contents of each issue of C $b R L$ News. Materials selected by the editor must be newsworthy, timely, and of practical value to people in the field. The editor has authority to decide what material is appropriate for publication, based on the following guidelines. The editor also reserves the right to make appropriate revisions in material selected for publication in order to standardize style or improve clarity (except official ACRL documents, president's letters, and similar material).

Formal, theoretical, or research-oriented articles inappropriate for C\&RL News will be forwarded to the editor of College \& Research Libraries for review.

\section{Length}

Articles and columns should be no more than 3,000 words and no less than 500 words.

\section{Style}

$C \mathcal{U} R$ News style is informal, but informative and accurate.

\section{Content}

Materials selected should fall into one of the following categories:

a. Reports on a project, program, or research underway or recently completed dealing with a topic relevant to academic librarianship. Footnotes should be minimal and charts or tables avoided. These reports may be preliminary descriptions of programs or research to be published formally at a later date in library literature (e.g., "Involving Classroom Faculty in the Reference Function," February 1986).

b. Reports on a recent conference or workshop of interest to academic or research librarians (e.g., “Towards a Digital World," October 1985).

c. Reasoned and informed speculation or comment on a relevant topic, especially if solicited by the editor or an official ACRL group (e.g. , "Bibliographic Instruction for Study Abroad Programs," November 1985).

d. State-of-the-art reports on a relevant topic (e.g., "The Scholar's Workstation," November 1985).

e. Standards, guidelines, or recommendations of an ACRL committee or other official ACRL group (e.g., "Draft Guidelines for Publishers of Conference Proceedings," February 1986). 


\section{ACQUISITION PERSPECTIVES}

3. We provide each customer a listing of books not immediately available from the publisher. This monthly open order report assures you we have recently taken effective action towards earliest possible delivery of your orders. Publisher stock status and additional information are available on a continuous computer printout or on individual $3 \times 5$ slips for easy filing. We cancel only publisher-documented out-of-print or out-of-stock-indefinitely titles.

Eliminate your claiming and begin receiving your open order reports from Book House.

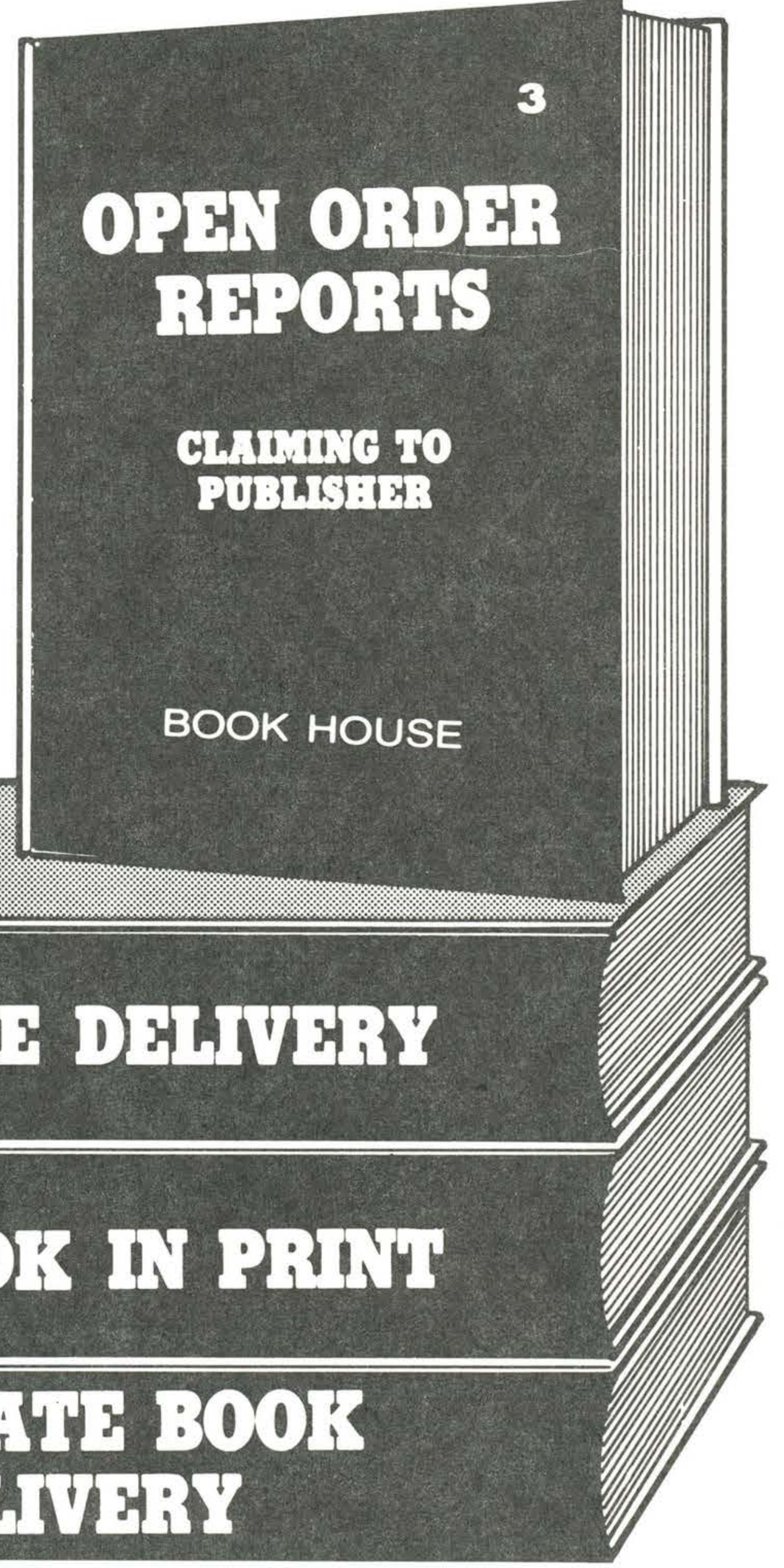

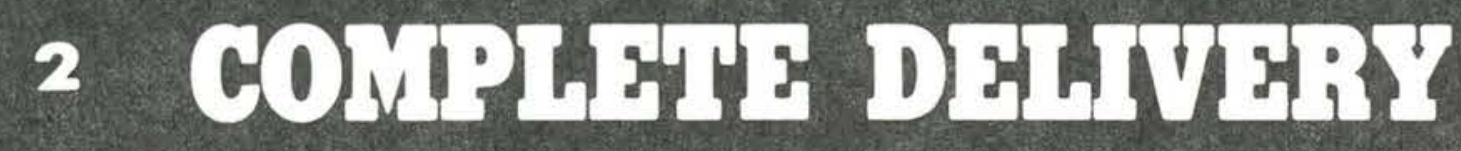

1 ANT BOOK II PRTH

4 ACGURFYW BOOR DHAVHA?

CALL TOLL-FREE TODAY

1-800-248-1146

In Canada \& Michigan

CALL COLLECT (517) 849-2117

OCLC Vendor No. 17397

SAN 169-3859

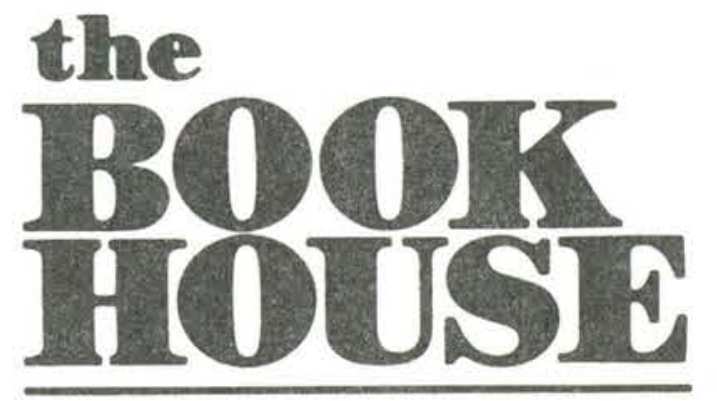

JOBBERS SERVING LIBRARIES WITH ANY BOOK IN PRINT SINCE 1962 208 WEST CHICAGO STREET JONESVILLE, MICHIGAN 49250 


\section{Manuscript}

Authors should submit two copies, doublespaced, following either the Chicago Manual of Style or Turabian.

The preferred typewriter elements are: Courier 10, Prestige Elite 12, or Letter Gothic 12.

Hyphenated word breaks should be avoided.

\section{Requests for Donations}

$C \downarrow R L$ News may occasionally print requests for the donation of books or materials to libraries, especially foreign libraries, which have suffered extensive loss through fire, hurricane, or other natural disaster. Other libraries soliciting contributions for other reasons will be referred to the rates for classified advertising in C $U R L$ News.

Editor's Note: These guidelines were adopted by the C\&RL News Editorial Board at the Denver Midwinter Meeting on January 25, 1982.

\title{
Involving classroom faculty in the reference function
}

\author{
By Bonnie Gratch \\ Head/Coordinator of Reference Service \\ Bowling Green State University
}

\section{English instructors answer questions at a special Research Paper Assistance Desk.}

\begin{abstract}
$\mathbf{S}_{\mathrm{i}}$ milar to many medium or large academic libraries, at Bowling Green State University in Ohio we have a course-integrated, research paper skills instructional component in the required English 112 class. Since over 3,000 freshmen enroll in this course during Spring semesters, we have developed a packet of written materials with a self-guided tour, corrected by library support 'staff, and research strategy exercises, corrected by classroom instructors, to completely replace library faculty class presentations. However, observations at the reference desk and a desire to promote increased librarian-student interaction were responsible for a plan to involve ENG 112 instructors and library faculty in a more direct way.

Although the library research paper strategy materials were a help to students, many students
\end{abstract}

still required assistance at the reference desk in researching their paper topics. The volume of questions generated by these students was straining the limits of the reference staff, even with our normal double staffing at peak times. In order to give the freshmen improved service and lighten the load at the reference desk, a separate service location was created.

A small table and chair were placed in the main entrance area across from the reference desk. A sign identified the table location as "ENG 112 Research Paper Assistance" and it listed the hours of staffing. In addition to two library faculty, we recruited two ENG 112 instructors to provide reference assistance six hours a day, five days a week over a five-week period. Reference desk statistics from prior semesters assisted us in selecting the 